\title{
Analisis Kelayakan Usahatani Jamur Tiram (pleurotus ostreatus) \\ Kasus: Petani Jamur Tiram di Desa Peguyangan Kaja Kecamatan Denpasar Utara
}

\author{
IDA BAGUS SAHADEWA, RATNA KOMALA DEWI \\ IDA AYU LISTIA DEWI
}

\author{
Program Studi Agribisnis, Fakultas Pertanian, Universitas Udayana \\ Jl. PB. Sudirman Denpasar 80232 Denpasar, Bali \\ Email: ibsahadewa@gmail.com \\ ratnadewi61@ymail.com
}

\section{Abstract \\ Analysis of Oyster Mushroom (pleurotusostreatus) \\ (The Case of Oyster Mushroom Farmers in Peguyangan KajaVillage, North Denpasar Sub-District)}

The development of oyster mushrooms (pleurotusostreatus) is enough to encourage mushroom farming in Indonesia. The same thing was done by the farmers of PeguyanganKaja Village, North Denpasar Sub-District, who were involved in oyster mushroom farming. This research was conducted in August 2017 through December 2017. The purpose of this study was to determine the feasibility of oyster mushroom business, analyzed using Net Present Value (NPV) investment criteria, Net benefit cost ratio (Net B / C), Internal rate of return (IRR), Payback Period (PBP), and Sensitivity analysis and knowing the constraints experienced by farmers in cultivating oyster mushrooms.

Based on the research and the results of the analysis that has been done, the following conclusion can be arrived at. Oyster Mushroom Farming with a capacity of 1.000, $2.500,3.000,5.000$ and 6.000 baglogs worthy of being farmed with an interest rate of $12 \%$, this is aimed at NPV $>0$ (positive), Net B / C $>0$ (positive), IRR $>\mathrm{i}$ that is $12 \%$, and $\mathrm{PP}<$ Economic age of mushroom media (5 years) and, sensitivity analysis based on the three sensitivity analyses, oyster mushroom farming at media mushroom capacity 5,000 baglogs is not sensitive to, increases in operational costs, decreases in production quantity and decreases the selling price of $10 \%$. Constraints faced in the cultivation of oyster mushrooms in the village of PeguyanganKaja, which is lowland, are that it is difficult to obtain a level of humidity between $80 \%$ and $100 \%$, which of course is easier to do if it is in the highland.

Keywords: farming, oyster mushroom, feasibility analysis, constraints 


\section{Pendahuluan}

\subsection{Latar Belakang}

Jamur tiram (pleurotus ostreatus) atau jamur tiram putih saat ini banyak diminati karena merupakan bahan olahan pangan yang lezat, sehat dan inovatif. Budidayanya pun mudah dan murah, sehingga berkembang pesat di Indonesia (Agromedia, 2010). Hal yang menarik dari budidaya jamur adalah memiliki nilai ekonomis yang cerah karena tidak membutuhkan lahan yang luas, Selain itu jamur tiram memiliki kandungan nutrisi yang sangat baik bagi kesehatan dan dipercayai mempunyai khasiat obat untuk menyembuhkan berbagai macam penyakit, dan jamur tiram merupakan jenis sayuran yang paling unggul dibandingkan dengan sayuran lain karena kandungan gizinya yang tinggi (Soenanto, 2000).

Desa Peguyangan Kaja Kecamatan Denpasar Utara sudah banyak yang meggeluti usaha budidaya jamur tiram, bahkan merupakan salah satu desa penghasil jamur tiram di Denpasar, meskipun belum dikelola atau dibudidayakan secara maksimal namun sudah memberikan sumber pendapatan bagi keluarga petani. Petani-petani jamur tiram di Desa Peguyangan Kaja dalam melakukan budidaya dengan sekala kecil yaitu $50 \mathrm{~kg}$ sampai dengan $100 \mathrm{~kg}$ per hari atau dua sampai dengan tiga ton per bulan di setiap usahataninya (Winda Andriani, 2014).

Tentunya setiap usahatani membutuhkan pengorbanan modal yang diinvestasikan dalam usaha tersebut. Seorang pengusaha tidak hanya melihat peluang-peluang usaha saja, tetapi harus cermat memperhitungkan apakah usaha yang dilaksanakan akan memberikan keuntungan atau tidak. Oleh sebab itu perlu dilakukan analisis kelayakan usaha pada usahatani jamur tiram di Desa Peguyangan Kaja Kecamatan Denpasar Utara Kota Denpasar agar jangan sampai usaha tersebut putus sebelum memberikan keuntungan (Mosher, 1987).

\subsection{Rumusan Masalah}

Berdasarkan uraian latar belakang di atas yang telah dipaparkan maka dapat dirumuskan permasalahan sebagai berikut.

1 Bagaimana kelayakan usahatani jamur tiram di Desa Peguyangan Kaja Kecamatan Denpasar Utara Kota Denpasar.?

2 Apa kendala-kedala yang dihadapi dalam usahatani jamur tiram di Desa Peguyangan Kaja Kecamatan Denpasar Utara Kota Denpasar?

\section{Metode Penelitian}

\subsection{Lokasi dan Waktu Penelitian}

Lokasi penelitian dilaksanakan di Desa Peguyangan Kaja Kecamatan Denpasar Utara Kota Denpasar Provinsi Bali. Penelitian ini dilaksanakan pada bulan Agustus 2017 sampai dengan Januari 2018. Pemilihan loksi penelitian di lakukan secara purposive dengan pertimbanga Petani Jamur Tiram Desa Peguyangan Kaja merupakan perintis usaha jamur tiram tahun 2009 dan salah satu desa yang memproduksi jamur tiram di Kota Denpasar. (Singarimbun dan Efendi, 1989).

\subsection{Data Penelitian}

Jenis data yang digunakan dalam penelitian ini adalah data kuantitatif dan data kualitatif. Data kuantitatif didalam penelitian ini adalah karakteristik responden yang meliputi umur, jumlah tanggungan, dan tingkat pendidikan. Data kualitatif, yaitu data 
yang dinyatakan dalam bentuk keterangan-keterangan dan uraian-uraian yang diperoleh dari unsur-unsur kedinamisan kelompok melalui pendekatan sosiologis. Metode yang dipergunakan dalam memperoleh data pada penelitian ini adalah surve, wawancara, dan dokumentasi dengan instrument data yang dipergunakan adalah kuesioner (Hendry, 2013).

\subsection{Populasi dan Responden Penelitian}

Populasi dalam penelitian ini adalah seluruh petani Jamur Tiram di Desa Peguyangan Kaja Kecamatan Denpasar Utara. Jumlah populasi adalah delapan orang petani dan Sampel diambil dengan menggunakan metode sensus (Mantra dan Kasto, 1987).

\subsection{Metode Analisis Data}

Data yang di peroleh dalam penelitian ini akan dianalisis sesuai dengan tujuan penelitian.

Kelayakan usaha jamur tiram pada usahatani di Desa Peguyangan Kaja Kecamatan Denpasar Utara Kota Denpasar. Dianalisis menggunakan metode deskriptif kuantitatif dengan pendekatan kreteria investasi. Sebelum dilakukan analisis kreteria investasi perlu dipertimbangkan asumsi-asumsi awal yaitu.

1. Usia petani dianggap sama atau dirata-ratakan.

2. Harga jual produk pertahun

3. Jumlah produksi pertahun

4. Biaya reinvestasi untuk alat-alat diasumsikan sama dengan harga beli awal. Adapun tahapan analisis awal kreteria investasi yang dilakukan yaitu.

a. $\quad$ Net present value (NPV)

Net present value dihitung dengan rumus sebagai berikut.

$$
N P V=\sum_{t=0}^{n} \frac{B_{t}-C_{t}}{(1+i)^{t}}
$$

Keterangan :

$\mathrm{Bt}=$ Benefit dari harga jual Jamur Tiram Per $/ \mathrm{kg}$

$\mathrm{Ct}=$ total niaya usahatani jamur tiram

yang dikeluarkan usahatani jamur tiram per tahun.

$\mathrm{i}=$ Tingkat bunga yang digunakan $12 \%$

$\mathrm{t} \quad=$ Waktu pelaksanaan tahun ke- $\mathrm{t}=1,2,3 \ldots, \mathrm{n}$.

$\mathrm{n} \quad=$ lamanya periode waktu 5 tahun.

Kriteria untuk menerima dan menolak rencana bisnis dengan metode $N P V$ adalah.

1. Apabila $N P V<0$, berarti usahatani jamur tiram tersebut tidak layak dilanjutkan.

2. Apabila $N P V>0$, berarti usahatani jamur tiram tersebut layak dilanjutkan.

3. Apabila $N P V=0$, berarti usahatani jamur tiram tersebut tidak memperoleh keuntungan dan kerugian.

b. $\quad$ Net benefit cost ratio $($ Net $B / C)$

$\mathrm{Net} \mathrm{B} / \mathrm{c}$ dihitung dengan rumus sebagai berikut.

$$
\text { Net } B / C=\frac{N P V(+.}{N P V(-7)}
$$


c. Internal rate of return (IRR)

$I R R$ dihitung dengan rumus sebagai berikut.

$$
\sum_{t=1}^{n}\left(B_{t}-C_{t}\right) /(1+i)^{t}=0 \text { atau } N P V=0
$$

Keterangan :

$B_{t}$ adalah manfaat proyek per tahun;

$C_{t}$ adalah biaya proyek per tahun;

$n$ adalah umur ekonomis proyek;

$i$ adalah tingkat bunga (discount rate) yang menyebabkan $N P V=0$

Adapun kriteria dari IRR yaitu :

Jika IRR $\geq$ i, maka $N P V \geq 0$, usaha usahatani jamur tiram bermanfaat dan layak untuk dijalankan dan Jika IRR $<\mathrm{i}$, maka $N P V<0$, usahatani jamur tiram tidak layak untuk dijalankan.

d. Payback Period (PP)

Payback period dihitung dengan rumus sebagai berikut.

$$
\mathrm{PP}=\mathrm{t}+\frac{b}{\mathrm{v}}(12 \text { bulan })
$$

Keterangan

$\mathrm{t}$ : periode terakir dimana jumlah cash inflow belum menutupi initial investment

$\mathrm{b}$ : komulatif cash inflow pada periode ke $\mathrm{t}$

c : cash inflow pada period ke $\mathrm{t}+1$

e. Analisis kepekaan (sensitivity analysis)

Analisis sensitivitas yang di pergunakan adalah sebagai berikut.

a. Peningkatan biaya oprasional usahatani jamur tiram sebesar $10 \%$

b. Produksi jamur tiram turun sebesar $10 \%$

c. Penurunan harga jual jamur tiram sebesar $10 \%$.

Analisis kepekaan dilakukan untuk melihat sampai berapa persen penurunan harga atau kenaikan biaya yang terjadi dapat mengakibatkan perubahan dalam kriteria investasi (Kasmir, 2003).

Mengetahui kendala kendala yang dialami petani dalam berusahatani jamur tiram di Desa Peguyangan Kaja Kecamatan Denpasar Utara Kota Denpasar dianalisis dengan metode deskriptif kualitatif.

\section{Hasil dan Pembahasan}

\subsection{Karakteristik Responden}

Karakteristik responden dalam penelitian ini adalah orang-orang yang melakukan kegiatan berusahatani jamur tiramn yang berjumlah delapan responden. Usia responden termasuk dalam usia produktif (BPS 2016). yang termasuk dalam golongan usia produktif adalah usia 15 tahun s.d. 64 tahun. Berdasarkan tingkat usia tersebut, 
responden mampu memberikan respon terhadap perubahan-perubahan informasi ataupun teknik dalam bekerja hingga memberikan hasil yang lebih baik.

\subsection{Kelayakan Finansial Usahatani Jamur Tiram di Desa Peguyangan Kaja}

Dalam menganalisis kelayakan usahatani jamur tiram ini dipergunakan beberapa perhitungan-perhitungan yang digunakan yaitu investasi, perkiraan pembelian bibit atau baglog, perkiraan produksi, biaya operasional, penerimaan, perhitungan kriteria investasi, dan analisis sensitivitas.

\subsubsection{Investasi}

Investasi yang dimaksud adalah sewa tanah, kumbung, selang, sprayer, gunting, pisau, kranjang plastik, peralatan tersebut dibeli pada tahun pertama yaitu tahun 2017. Biaya investasi dapat dilihat pada Tabel 1 berikut.

Tabel 1.

Investasi Usahatani Jamur Tiram Selama Umur Ekonomis Kumbung

\begin{tabular}{|c|c|c|c|c|c|c|}
\hline \multirow{3}{*}{ No } & \multirow{3}{*}{ Keterangan } & \multicolumn{5}{|c|}{$\begin{array}{c}\text { Biaya Investasi } \\
(\mathrm{Rp})\end{array}$} \\
\hline & & \multicolumn{5}{|c|}{ Kapasitas kumbung (Baglog) } \\
\hline & & 1.000 & 2.500 & 3.000 & 5.000 & 6.000 \\
\hline 1 & Sewa tanah & 1.400 .000 & 2.100 .000 & 2.100 .000 & 4.200 .000 & 7.000 .000 \\
\hline 2 & Kumbung & 7.317 .000 & 11.485 .000 & 11.485 .000 & 22.650 .000 & 35.850 .000 \\
\hline 3 & Selang & 25.000 & 50.000 & 50.000 & 75.000 & 75.000 \\
\hline 4 & Seprayer & 300.000 & 30.000 & 300.000 & 600.000 & 600.000 \\
\hline 5 & Gunting & 20.000 & 60.000 & 60.000 & 80.000 & 80.000 \\
\hline 6 & Pisau & 30.000 & 90.000 & 90.000 & 120.000 & 180.000 \\
\hline 7 & Kranjang & 100.000 & 200.000 & 300.000 & 400.000 & 500.000 \\
\hline & Total & 9.192 .000 & 14.285 .000 & 14.38 .5000 & 28.125 .000 & 44.285 .000 \\
\hline
\end{tabular}

Sumber: Data Primer (2017)

Adapun nilai sisa bangunan tersebut dinilai 10\% dari harga beli (Gittinger, 2008). Dan untuk nilai sisa selang, sprayer, gunting, pisau, dan kranjang plastik dinilai dari $15 \%$ harga beli. Nilai sisa tersebut adalah keuntungan non tunai yang akan di peroleh petani. Biaya investasi untuk nilai sisa dapat dilihat pada Tabel 2 berikut.

Tabel 2.

Investasi Nilai Sisa Jamur Tiram Selama Umur Ekonomis Kumbung

\begin{tabular}{rlrrrrr}
\hline & & \multicolumn{5}{c}{ Nilai Sisa } \\
No & \multirow{5}{c}{ Kap $)$} \\
\cline { 3 - 7 } & & \multicolumn{5}{c}{ Keterangatas kumbung $($ Baglog) } \\
\cline { 3 - 7 } & & 1.000 & 2.500 & \multicolumn{1}{c}{3.000} & \multicolumn{1}{c}{5.000} & \multicolumn{1}{c}{6.000} \\
\hline 1 & Sewa tanah & - & - & - & - \\
2 & Kumbung & 731.700 & 1.148 .500 & 1.148 .500 & 2.265 .000 & 3.585 .000 \\
3 & Selang & 3.750 & 7500.000 & 7.500 & 11.250 & 11.250 \\
4 & Seprayer & 150.000 & 150.000 & 150.000 & 300.000 & 300.000 \\
5 & Gunting & 10.000 & 30.000 & 30.000 & 40.000 & 40.000 \\
6 & Pisau & 15.000 & 45.000 & 45.000 & 60.000 & 90.000 \\
7 & Kranjang & 50.000 & 100.000 & 150.000 & 200.000 & 250.000 \\
\hline & Total & 960.450 & 1.481 .000 & 1.531 .000 & 2.876 .250 & 4.276 .250 \\
\hline
\end{tabular}

Sumber: Data Primer(2017) 
Pada Tabel 1, Tabel 2 terlihat bahwa Gunting pisau dan kranjang plasting berfungsi untuk saat jamur tiram di panen. Sprayer, gunting, pisau, dan keranjang plastik memiliki umur ekonomis dua tahun sehingga tahun ketiga dan kelima di beli lagi.

\subsubsection{Biaya baglog}

Baglog merupakan yang utama diperlukan dalam usahatani jamur tiram. Pembelian baglog diasumsikan berdasarkan kapasitas maksimal kumbung. Harga baglog diasumsikan tetap berdasarkan rata-rata harga pada saat tahun 2017. Jumlah baglog yang diperlukan setiap tahunnya dapat dilihat pada Tabel 3 berikut.

Tabel 3.

Perkiraan Biaya baglog Selama Umur Ukonomis Kumbung

\begin{tabular}{ccccc}
\hline No & $\begin{array}{c}\text { Kapasitas } \\
\text { Kumbung } \\
\text { (baglog) }\end{array}$ & $\begin{array}{c}\text { Harga } \\
\text { Satuan } \\
\text { Baglog } \\
(\mathrm{Rp})\end{array}$ & $\begin{array}{c}\text { Biaya Baglog } \\
\text { Satu kali } \\
\text { Periode Panen } \\
(\mathrm{Rp})\end{array}$ & $\begin{array}{c}\text { Biaya Baglog } \\
\text { Dalam Satu } \\
\text { Tahun } \\
(\mathrm{Rp})\end{array}$ \\
\hline 1 & 1.000 & 5.000 & 5.000 .000 & 15.000 .000 \\
2 & 2.500 & 5.000 & 12.500 .000 & 37.500 .000 \\
3 & 3.000 & 5.000 & 15.000 .000 & $45,000,000$ \\
4 & 5.000 & 5.000 & 25.000 .000 & 75.000 .000 \\
5 & 6.000 & 5.000 & 30.000 .000 & 90.000 .000 \\
\hline
\end{tabular}

Keterangan: dalam satu tahun terdapat tiga kali pembelian baglog Sumber : Data Primer

Pada Tabel 3 di atas, dapat diketahui bahwa asumsi untuk pembelian baglog setiap satu periodenya untuk baglog yang paling sedikit adalah Rp5.000.000, dan yang paling tinggi biaya pembelian baglognya adalah Rp30.000.000, dengan kapasitas 6.000 baglog. Dalam satu tahunnya ada tiga kali periode pembelian baglog dengan biaya sebesar Rp15.000.000 untuk kapasitas 1.000 baglog dan Rp 90.000.000 untuk kapasitas 6.000 baglog. Asumsi pembelian baglog adalah pembelian kapasitas maksimal kumbung.

\subsubsection{Biaya operasional}

Biaya operasional adalah biaya yang diperlukan pada saat proses produksi berlangsung dalam Usahatani Jamur Tiram, biaya terebut terdiri dari biaya setiap tahunnya dapat dilihat pada Tabel 4 berikut.

$$
\text { Tabel } 4
$$

Biaya Operasional Jamur Tiram Dalam Satu Tahun

\begin{tabular}{ccccc}
\hline $\begin{array}{c}\text { Kapasitas } \\
\text { Kumbung } \\
(\text { baglog })\end{array}$ & $\begin{array}{c}\text { Biaya } \\
\text { Baglog } \\
(\mathrm{Rp} / \mathrm{thn})\end{array}$ & $\begin{array}{c}\text { Biaya } \\
\text { Input } \\
(\mathrm{Rp} / \mathrm{thn})\end{array}$ & $\begin{array}{c}\text { Biaya } \\
\text { Tenaga Kerja } \\
(\mathrm{Rp} / \mathrm{thn})\end{array}$ & $\begin{array}{c}\text { Total Biaya } \\
(\mathrm{Rp})\end{array}$ \\
\hline 1.000 & 15.000 .000 & 751.500 & 4.753 .125 & 20.504 .625 \\
2.500 & 37.500 .000 & 2.880 .000 & 12.521 .250 & 52.901 .250 \\
3.000 & 45.000 .000 & 3.210 .000 & 16.571 .250 & 64.781 .250 \\
5.000 & 75.000 .000 & 5.317 .500 & 17.448 .750 & 97.766 .250 \\
6.000 & 90.000 .000 & 6.795 .000 & 19.890 .000 & 116.685 .000 \\
\hline
\end{tabular}

Sumber: Data Primer Diolah (2017) 
Dari Tabel 4 di atas, biaya operasional tertinggi terdapat pada pembelian baglog karena tiap tahun kebutuhan bahan baglog banyak. Sedangkan biaya operasional terendah terdapat pada biaya input, biaya input di dalamnya adalah kebutuhan air, listrik, tas plastik, dan premium.

\subsubsection{Perkiraan produksi}

Berikut adalah perkiraan produksi jamur tiram di Desa Peguyangan Kaja dapat dilihat pada Tabel 5.

Tabel 5

Perkiraan Produksi Jamur Tiram Selama Umur Ekonomis Kumbung

\begin{tabular}{|c|c|c|c|c|c|c|c|c|}
\hline \multirow{2}{*}{$\begin{array}{c}\text { Tahun } \\
\text { ke }\end{array}$} & \multirow{2}{*}{$\begin{array}{c}\text { Kapasitas } \\
\text { Kum- } \\
\text { bung } \\
\text { (baglog) }\end{array}$} & \multirow{2}{*}{$\begin{array}{c}\text { Keber- } \\
\text { hasilan } \\
\text { tumbuh } \\
(\%)\end{array}$} & \multirow{2}{*}{$\begin{array}{l}\text { Baglog } \\
\text { yang } \\
\text { tumbuh } \\
\text { (unit) }\end{array}$} & \multirow{2}{*}{$\begin{array}{c}\text { Produksi } \\
\text { (Kg/bag- } \\
\text { log) }\end{array}$} & \multicolumn{3}{|c|}{ Produksi (kg/periode) } & \multirow{2}{*}{$\begin{array}{l}\text { Pro- } \\
\text { duksi } \\
(\mathrm{Kg} / \\
\text { thn })\end{array}$} \\
\hline & & & & & $\mathrm{p} 1$ & & & \\
\hline 1 & & 80 & 800 & & & & & 1.200 \\
\hline 2 & & 80 & 2.000 & & & & & 3.000 \\
\hline 3 & 3. & 80 & 2.400 & & 0 & 1.2 & & 3.600 \\
\hline 4 & 5.000 & 80 & 4.000 & & 2.000 & 2.000 & 2.000 & 6.000 \\
\hline 5 & 6.000 & 80 & 4.800 & 0,5 & 2.400 & 2.400 & 2.400 & 7.200 \\
\hline
\end{tabular}

Sumber : Data Primer diolah (2017)

Keterangan : p1,p2, dan p3 adalah periode produksi jamur tiram, karena dalam satu tahun terdapat tiga kali periode produksi.

Pada Tabel 5 di atas, keberhasilan tumbuh dari baglog adalah $80 \%$, sehingga dari kapasita kumbung tersebut diperolehlah baglog yang berhasil tumbuh kemudian dikalikan produksi per satu baglognya yang menghasilkan $0,5 \mathrm{~kg}$ jamur tiram, sehingga diperolehlah produksi jamur tiram setiap satu kali periode panen perkapasitas kumbung. Sedangkan dalam satu tahun terdapat tiga kali periode panen, sehingga periode satu da dan tida dijumlahkan untuk mendapatkan produksi jamur tiram pertahunnya.

\subsubsection{Penerimaan}

Penerimaan adalah harga jual jamur tiram dikalikan dengan jumlah produksinya, dari tahun pertama sampai tahun sampai kelima dengan asumsi semua hasil terjual. Adapun penerimaana dapat dilihat dalam Tabel 6 berikut.

Tabel 6.

Penerimaan Jamur Tiram Selama Umur Ekonomis Kumbung

\begin{tabular}{cccccc}
\hline \multirow{2}{*}{$\begin{array}{c}\text { Tahun } \\
\text { ke }\end{array}$} & \multicolumn{5}{c}{$\begin{array}{c}\text { Penerimaan (Kg/Tahun) } \\
\text { Kapasitas Kumbung }\end{array}$} \\
\cline { 2 - 6 } & 1.000 & 2.500 & 3.000 & 5.000 & 6.000 \\
\hline 1 & 24.000 .000 & 60.000 .000 & 72.000 .000 & 120.000 .000 & 144.000 .000 \\
2 & 24.000 .000 & 60.000 .000 & 72.000 .000 & 120.000 .000 & 144.000 .000 \\
3 & 24.000 .000 & 60.000 .000 & 72.000 .000 & 120.000 .000 & 144.000 .000 \\
4 & 24.000 .000 & 60.000 .000 & 72.000 .000 & 120.000 .000 & 144.000 .000 \\
5 & 24.000 .000 & 60.000 .000 & 72.000 .000 & 120.000 .000 & 144.000 .000 \\
\hline
\end{tabular}

Sumber: Data Primer Diolah (2017)

Pada Tabel 6 di atas, jumlah produksi jamur tiram pada Tabel 5, dikalikan dengan harga jamur tiram yaitu, Rp.20.000,00 maka diperolehlah penerimaan petani. 


\subsubsection{Pendapatan usahatani jamur tiram} berikut.

Usahataninya memperoleh keuntungan atau tidak, dapat dilihat pada Tabel 7

Tabel 7.

Penerimaan Jamur Tiram Selama Umur Ekonomis Kumbung

\begin{tabular}{crrrrr}
\hline \multirow{2}{*}{$\begin{array}{c}\text { Kapasitas } \\
\text { Kumbung } \\
(\text { Baglog })\end{array}$} & \multicolumn{1}{c}{\begin{tabular}{c} 
(Rp/Tahun) \\
\cline { 2 - 6 }
\end{tabular}} & \multicolumn{1}{c}{2} & \multicolumn{1}{c}{3} & \multicolumn{1}{c}{4} & \multicolumn{1}{c}{5} \\
\hline 1.000 & -5696.625 & 3.495 .375 & 3045.375 & 3.495 .375 & 4.005 .825 \\
2.500 & -7186.250 & 7.098 .750 & 6.448 .750 & 7.098 .750 & 7.929 .750 \\
3.000 & -7.166 .250 & 7.218 .750 & 6.468 .750 & 7.218 .750 & 7.999 .750 \\
5.000 & -5.891 .250 & 22.233 .750 & 21.033 .750 & 22.233 .750 & 23.910 .000 \\
6.000 & -16.970 .000 & 27.315 .000 & 25.955 .000 & 27.315 .000 & 30.231 .250 \\
\hline
\end{tabular}

Sumber: Data Primer Diolah (2017)

Pada Tabel 7 di atas, nilai sisa dari biaya investasi ditambah dengan penerimaan kemudian di kurangi biaya investasi pada Tabel 1,biaya oprasional pada Tabel 4 dan diperolehlah penerimaan bersih petani Jamur Tiram. perhitungan penerimaan dan total biaya dilakukan selama umur ekonomis kumbung yaitu lima tahun.

\subsubsection{Perhitungan Kriteria Investasi}

Perhitungan kreteria investasi dengan analisis kreteria investasi yaitu NPV, Net B/C, IRR, dan Payback Periode,berdasarkan kapasitas kumbung, secara garis besar dapat dilihat pada Tabel 8 berikut.

Tabel 8.

Perhitungan Kreteria Investasi Selama Umur Ekonomis Kumbung

\begin{tabular}{ccccc}
\hline $\begin{array}{c}\text { Kapasitas } \\
\text { Kumbung } \\
(\text { Baglog })\end{array}$ & $\begin{array}{c}\text { NPV } \\
(\mathrm{Rp})\end{array}$ & Net B/C & IRR $(\%)$ & PP \\
\hline 1.000 & 4.362 .243 & 1,05 & 47,61 & 2 tahun 11 bulan \\
2.500 & 12.843 .815 & 1,06 & 89,70 & 2 tahun 2 bulan \\
3.000 & 13.087 .553 & 1,05 & 91,35 & 2 tahun 2 bulan \\
5.000 & 44.456 .394 & 1,12 & 327,25 & 1 tahun 4 bulan \\
6.000 & 59.611 .020 & 1,13 & 155,93 & 1 tahun 8 bulan \\
\hline
\end{tabular}

Sumber: Data Primer Diolah (2017)

Usahatani Jamur Tiram di desa peguyangan kaja adalah layak secara finansial karena NPV positip, IRR lebih besar dari 12\%, dan Net B/C lebih besar dari satu. Diperoleh nilai NPV terbesar ada pada kapasitas 6.000 baglog sebesar Rp 59,611,021 umur ekonomis dengan tingkat bunga 12\%. IRR yang tertinggi ada pada kapasitas 5.000 baglog sebesar 327,25\%. artinya usaha layak dijalankan karena IRR ini lebih besar dari tingkat suku bunga pada koperasi tersebut. Net B/C tertinggi ada pada kapasitas 6.000 baglog sebesar 1,13. Payback Periode terkecil ada pada kapasitas 5.000 baglog, sebesar 1 tahun 4 bulan. 


\subsubsection{Analisis Kepekaan (sensitivity analysis) pada Usahatani Jamur Tiram}

Analisis sensitivitas yang mungkin terjadi pada usahatani Jamur Tiram dapat dilihat pada Tabel 9 berikut.

Tabel 9.

Analisis Kepekaan (sensitivity analysis) Pada Usahatani Jamur Tiram

\begin{tabular}{|c|c|c|c|c|c|}
\hline No & Uraian & & & & \\
\hline \multirow[t]{7}{*}{1} & \multicolumn{5}{|c|}{ Peningkatan Biaya Oprasional 10\% } \\
\hline & $\begin{array}{c}\text { Kapasitas kumbung } \\
\text { (baglog) }\end{array}$ & $\begin{array}{l}\text { NPV } \\
\text { (Rp) }\end{array}$ & $\begin{array}{l}\mathrm{Net} \\
\mathrm{B} / \mathrm{C}\end{array}$ & $\begin{array}{l}\text { IRR } \\
(\%)\end{array}$ & PP \\
\hline & 1.000 & -3.029 .215 & 0,97 & - & - \\
\hline & 2.500 & -5.782 .610 & 0,98 & - & - \\
\hline & 3.000 & -10.497 .079 & 0,97 & - & - \\
\hline & 5.000 & 19.890 .554 & 1,05 & 68,8 & 2 tahun 5 bulan \\
\hline & 6.000 & 17.548 .690 & 1,03 & 40,82 & 3 tahun 2 bulan \\
\hline \multirow[t]{6}{*}{2} & \multicolumn{5}{|l|}{ Produksi Turun $10 \%$} \\
\hline & 1.000 & -6.452 .085 & 0,92 & - & - \\
\hline & 2.500 & -15.091 .407 & 0,94 & - & - \\
\hline & 3.000 & -20.337 .467 & 0,93 & - & - \\
\hline & 5.000 & 1.061 .456 & 1,00 & 14,58 & 4 tahun 7 bulan \\
\hline & 6.000 & -5.274 .951 & 0,99 & - & - \\
\hline \multirow[t]{6}{*}{3} & \multicolumn{5}{|c|}{ Penurunan Harga Jual Produk 10\% } \\
\hline & 1.000 & -4.289 .219 & 0,95 & - & - \\
\hline & 2.500 & -8.772 .861 & 0,96 & - & - \\
\hline & 3.000 & -12.755 .212 & 0,96 & - & - \\
\hline & 5.000 & 16.820 .307 & 1,04 & 43,12 & 2 tahun 11 bulan \\
\hline & 6.000 & 7.702 .244 & 1,02 & 23,73 & 4 tahun \\
\hline
\end{tabular}

Sumber: Data Primer Diolah ( 2017)

Berdasarkan Tabel 9 di atas nilai perhitungan analisis kepekaan (sensitivity analysis) peningkatan biaya oprasional sebesar 10\%, pada kapasitas (1.000, 2.500 dan 3.000) baglog NPV negative, penurunan produksi sebesar $10 \%$ pada kapasitas $(1.000$, 2.500, 3.000 dan 6.000) baglog NVP negatif, penurunan harga jual sebesar $10 \%$ Pada kapasitas (1.000, 2.500 dan 3.000) baglog NPV masih negative ini menunjukkan bahwa usaha ini sudah tidak layak dilanjutkan karena usahataninya tidak menguntungkan dan tidak layak di jalankan. Pada kapasitas 5.000 baglog NPV positif, berarti pada kapasitas 5.000 baglog saja tidak terpengaruh terhadap ketiga analisis kepekaan tersebut, sedangkan pada kapasitas 6.000 baglog hanya terpengaruh pada penurunan produksi sebesar $10 \%$ saja.

\subsection{Kendala-kedala yang Dihadapi dalam Usahatani Jamur Tiram}

Kendala-kedala yang dihadapi dalam usahatani jamur tiram di Desa Peguyangan Kaja meliputi aspek teknis, yaitu lokasi usahatani jamur tiram yang berada pada dataran rendah. Meski di Desa Peguyangan Kaja bertempat di dataran rendah tentusaja budidaya jamur tiram bisa dilakukan, hanya saja produktivitasnya tidak sebaik di dataran tinggi. Hal ini di sebabkan jamur merupakan tanaman yang membutuhkan tingkat kelembaban antara $80 \%$ s.d $100 \%$

Perbedaan produktivitas pada lokasi usahatani jamur tiram tersebut tentu berpengaruh pada hasil panen. Jika di dataran tinggi menghasilkan dua ons jamur tiram https://ojs.unud.ac.id/index.php/JAA 
segar per baglognya lain halnya di dataran rendah, hanya 1 ons sampai 1,5 ons jamur tiram segar karena di dataran rendah cuacanya lebih hangat dibandingkan didataran tinggi, ini menyebabkan tumbuh kembang jamur menjadi lambat yang menyebabkan tingkat produksi menurun untuk di dataran rendah.

\section{Simpulan dan Saran}

\subsection{Simpulan}

Berdasarkan penelitian dan hasil analisis yang telah dilakukan dapat disimpulkan berbagai simpulan yaitu sebagai berikut.

1. Usahatani Jamur Tiram dengan kapasitas kumbung 1.000, 2.500, 3.000, 5.000, dan 6.000 baglog layak untuk diusahatanikan dengan suku bunga $12 \%$, hal ini ditujukan pada NPV $>0$ (positif), Net B/C > 0 (positif), IRR $>$ i yaitu $12 \%$, dan PP < Umur ekonomis kumbung (5 tahun ) dan, Analisis kepekaan (sensitivity analysis) yang berdasarkan ketiga analisis kepekaan, usahatani jamur tiram pada kapasitas kumbung 5.000 baglog tidak sensitive terhadap, kenaikan biaya oprasional, penurunan kuantitas produksi dan, penurunan harga jual sebesar $10 \%$. Berdasarkan kendala-kedala yang dihadapi dalam usahatani jamur tiram di Desa Peguyangan Kaja Kecamatan Denpasar Utara Kota Denpasar, kurangnya lahan untuk berusahatani jamur tiram akibat bertambahnya pembangunan dan untuk saat ini pemasaran jamur tiram mengalami hambatan / kendala, karena adanya petanipetani jamur tiram lain yang ada di luar Denpasar juga usaha budidaya jamur tiram belum mampu menciptakan lapangan kerja bagi masyarakat, karena masi bersekala kecil.

2. Kendala yang dihadapi dalam usahatani jamur tiram di Desa Peguyangan Kaja yang merupakan dataran rendah sulit memperoleh tingkat kelembaban antara 80 $\%$ s.d $100 \%$ yang tentu saja lebih mudah di lakukan jika di dataran tinggi.

\subsection{Saran}

Berdasarkan simpulan, maka peneliti dapat memberikan saran kepada petani jamur tiram di Desa Peguyangan Kaja. Petani jamur tiram di sarankan melakukan usahatani jamur tiram dengan kapasitas kumbung 5.000 baglog, Pada kapasitas kumbung 5.000 baglog tidak sensitif terhadap kenaikan biaya oprasional, penurunan kuantitas produksi dan, penurunan harga jual sebesar 10\%. dengan kapasitas ini usahatani jamur tiram sangat layak di usahatanikan.

\section{Ucapan Terimakasih}

Terima kasih kepada seluruh anggota Subak Kerdung dan Pekaseh Subak Kerdung, Kelurahan Pedungan, Kecamatan Denpasar Selatan Kota Denpasar yang sudah bersedia menerima dan membantu penulis dengan menjadi responden maupun informan kunci penelitian. 


\section{Daftar Pustaka}

Agromedia. 2010 Bertanam Jamur Konsumsi. Agromedia pustaka Jakarta.

Badan Pusat Statistik (BPS) Denpasar.2017. Kota Denpasar Dalam Angka 2016.

Gittinger, JP. 2008. Analisa Ekonomi Proyek-proyek Pertanian. Edisi kedua, telah direvisi dan siperluas lengkap. Jakarta: UI-Press

Hendry. 2013. Metode Pengumpulan Data. Diunduh pada http://teorionline.wordpress.com/, pada tanggal 19 Agustus 2014

Kasmir, Jakfar. 2009. Studi Kelayakan Bisnis. Ed ke-2. Jakarta: Prenada Media Group.

Mantra ida Bagus dan Kasto, 1987. Penentuan Sampel dalam Singa rimbun. Metode Penelitian Suvai LP3ES. Jakarta

Mosher, A. T, 1987. Menggerakkan dan Membangun Pertanian. Yasaguna, Jakarta.

Singarimbun, M dan Efendi, S. 1989. Metode Penelitian Survei. LP3ES

Soenanto, H. 2000. Jamur Tiram, Budidaya dan Peluang Usaha. Semarang : Aneka ilmu.

Winda Andriani. 2014 Perencanaan Pemasaran Usahatani Jamur Tiram, Denpasar 